Revista de Antropología Social

ISSN: 1131-558X

http://dx.doi.org/10.5209/RASO.61851

\title{
La donación anónima de óvulos en Europa. Los problemas sobre el discurso de «donar vida»
}

\author{
Noelia Igareda González ${ }^{1}$
}

Recibido: 20 de diciembre de 2017/Aceptado: 04 de junio de 2018

Resumen. La Unión Europea no tiene competencias en materia de técnicas de reproducción humana asistida y esto provoca una diversidad legal en Europa, especialmente sobre donación de óvulos y anonimato. Dado que existe la libertad de movimiento de personas, servicios, bienes y capitales dentro del espacio común europeo, el llamado turismo reproductivo se ha incrementado y extendido. España se ha convertido en uno de los destinos reproductivos más buscados, gracias a una legislación permisiva y a la disponibilidad de gametos donados, principalmente óvulos. Este artículo identifica los principales argumentos utilizados para legitimizar la donación de gametos, y particularmente de óvulos, así como su anonimato. También aborda los problemas suscitados por su carácter altruista y las posibles situaciones de explotación de mujeres que cuestionan el discurso de donar vida.

Palabras clave. Donación de óvulos; donación anónima de gametos; turismo reproductivo; solidaridad de mujeres; técnicas de reproducción humana asistida.

\section{[en] The anonymous donation of occytes in Europe. Problems to the discourse about donating life}

\begin{abstract}
The European Union has no competencies concerning assisted reproductive techniques and this has resulted in regulatory diversity throughout Europe, in particular on oocyte donation and its anonymity. Given this diversity and the free movement of people, services, goods and capitals within the common European space, the so called reproductive tourism has increased and become widespread. Spain has become a preferred reproductive destination for this purpose due to its permissive legislation and the availability of donated gametes, especially oocyte. This article identifies different arguments used to legitimize the donation of gametes, and oocytes in particular, and the need for anonymity, meanwhile, problems about its altruistic character and the possible exploitation of women, put under question the discourse about donating life.
\end{abstract}

Keywords: Egg donation, anonymous gamete donation, reproductive tourism, women's solidarity, human assisted reproductive techniques.

Sumario: 1. La diversidad legal en Europa. 2. Las técnicas de reproducción humana asistida y las normas legales de filiación. 3. Algunos datos sobre la donación de óvulos en Europa que complican aún más el análisis. 4. Argumentos para legitimar la donación anónima de óvulos. 5. Problemas y críticas a la donación de óvulos. 6. El ambiguo discurso sobre donar vida. 7. Bibliografía.

Cómo citar: Igareda González, N. (2018). La donación anónima de óvulos en Europa. Los problemas sobre el discurso de "donar vida", en Revista de Antropología Social 27(1), 247-260.

$1 \quad$ Noelia.igareda@uab.cat 


\section{La diversidad legal en Europa}

El llamado turismo reproductivo, o movimiento transnacional reproductivo, hace alusión a los flujos de personas que viajan a países diferentes de los suyos de residencia, para poder acceder a técnicas de reproducción asistida, que en sus países de origen son ilegales, o son de más difícil acceso (Pennings, 2004). Aunque el turismo reproductivo es un fenómeno global, en el caso de la Unión Europea, cobra una especial relevancia, porque por un lado, son mayoritarios los flujos de ciudadanos de un Estado miembro a otro, y por otro, porque debido a ciertas características del espacio común europeo, como es la libre circulación de personas, bienes, capitales y servicios, este movimiento transnacional se hace más fácil, y a la vez, provoca problemas legales o éticos añadidos (Shenfield et al., 2010).

La Unión Europea no tiene competencias sobre reproducción humana, sobre técnicas de reproducción humana asistida, ni siquiera sobre donación de gametos. Únicamente existe una normativa europea relacionada, que es la Directiva 2004/23/CE del Parlamento Europeo y del Consejo, de 31 de marzo de 2004, relativa al establecimiento de normas de calidad y de seguridad para la donación, la obtención, la evaluación, el procesamiento, la preservación, el almacenamiento y la distribución de células y tejidos humanos, que permite la donación voluntaria y altruista de óvulos, aunque establece la posibilidad de compensar a la donante por los inconvenientes causados.

Esto ha dado lugar a una diversidad de legislaciones sobre el tema en la Unión Europea. Algunos países han considerado que la libertad procreativa que permiten las técnicas de reproducción humana asistida pueden a la vez constituir una amenaza para algunos derechos fundamentales, de ahí la intervención estatal para prevenir estos abusos (Alkorta, 2006). Este es por ejemplo el caso de Alemania o Austria², donde se han aprobado las legislaciones más restrictivas, en gran manera influidas por las dramáticas experiencias eugenésicas de principios del siglo XX (Vidal, 2011). La legislación italiana ${ }^{3}$ también es muy restrictiva, debido a la influencia de la Iglesia Católica y su postura moral contraria a las técnicas de reproducción humana asistida que disocian sexualidad y reproducción. El Reino Unido ${ }^{4}$ y España ${ }^{5}$ tienen, sin embargo, las legislaciones más permisivas.

Dentro de esta variedad legal sobre técnicas de reproducción humana asistida, son también muy diferentes los posicionamientos sobre la donación de gametos, aceptando o no la posibilidad o solo de semen. También son diversas las posturas legales sobre el carácter anónimo o no de esta donación.

La donación de óvulos está prohibida en Suiza, Austria y Alemania ${ }^{6}$. En Alemania esta prohibición se debe a la preocupación por el bienestar de los niños y la preocupación por poder siempre identificar quién es la madre. La separación de la

\footnotetext{
Ley Federal de Protección del Embrión de 1990 (Embryonenschutzgesetz), la Adoption Brokerage Law 2006, y Guideline of the German Federal Medical Chamber 2006.

Ley n. 40 (19/2/2004) Norma en materia de reproducción médicamente asistida

Human Fertilization and Embryology Act 2008 (Nov 2008).

Ley 14/2006 de 26 de marzo, sobre técnicas de reproducción humana asistida.

En Italia estaba prohibida por la Ley n. 40 (19/2/2004) hasta la sentencia del Tribunal Constitucional del 9 de abril de 2014 que suprimió la prohibición de inseminación heteróloga. No obstante, la ausencia de regulación específica, y la prohibición de compensación a donantes de gametos, hace que sea muy difícil obtener óvulos donados.
} 
maternidad genética y biológica se considera una amenaza al desarrollo emocional y a la estabilidad psíquica del niño/a (Farnós, 2016). En Suecia o Dinamarca, se pueden utilizar los óvulos sobrantes de ciclos de reproducción asistida porque el procedimiento de obtención de óvulos se considera peligroso para la salud de la donante. En Noruega, las identidades están muy determinadas biológicamente y la donación de óvulos está prohibida porque se considera contraria a la naturaleza, la maternidad y al interés superior del menor (Golombok, 2012). Un argumento común en estos países es que permitir la donación de óvulos contribuiría a la comercialización y explotación de las mujeres (Ahumada, 2008).

Al igual que existe diversidad legal en cuanto a la donación de gametos masculinos y femeninos en Europa, también existen diferencias normativas respecto al anonimato de donación de gametos. Algunos países han levantado el anonimato para garantizar el derecho a conocer los orígenes biológicos, Suecia fue el primer país en eliminar el anonimato en la donación de gametos en 1984 y también Austria cambió en este sentido su normativa en 1992 (en estos dos países solo se permite la donación de esperma y no de óvulos). En el 2000, Holanda también modificó el anonimato en la donación de gametos, y finalmente en 2005 fue el Reino Unido quien cambió su normativa para permitir el derecho a conocer los orígenes a los niños una vez cumplieran los 18 años?

En el presente artículo se identificarán los principales argumentos que se esgrimen para legitimar la donación de gametos en el marco de las técnicas de reproducción humana asistida, dentro de la citada diversidad legal europea. Y, por otro lado, se abordan los principales problemas que plantea la donación de gametos, especialmente de óvulos, así como su carácter anónimo y altruista.

\section{Las técnicas de reproducción humana asistida y las normas legales de filiación}

Es esencial comparar las leyes sobre técnicas de reproducción asistida con las reglas legales de filiación para poder entender algunos de los debates planteados en torno a la donación de óvulos. Las leyes sobre filiación en Europa se apoyan mayoritariamente en los lazos de sangre para establecer relaciones familiares. La sangre se utiliza como metáfora para explicar cómo la filiación se establece social y legalmente y para denominar lo que convierte en familiares a las personas (Golombok, 2012). De esta forma los vínculos de filiación quedan determinados por la sangre, los genes y la biología, siendo esencial ser considerados parientes para poder ser reconocidos legalmente como familiares.

Hasta hace relativamente poco, la única manera legítima de establecer filiación en Europa era a través del matrimonio, lo que distinguía a los hijos/as legítimos e ilegítimos, independientemente de los lazos de sangre. El matrimonio permitía la aplicación de los principios legales pater vero est quem nuptiae demonstrant (el padre real queda determinado por el matrimonio) y mater semper certa est (la certeza de la maternidad determinada por la mujer que pare) (Casado, 1997).

Estas reglas generales de filiación han estado vigentes legalmente en Europa desde el derecho romano. Tienen un claro impacto de género ya que la paternidad queda social o legalmente determinada, mientras que la maternidad se define biológicamente.

Human Fertilization and Embryology Authority (disclosure of Donor Insemination) Regulations, 2004. 
La donación de óvulos constituye un reto a la presunción de la maternidad, mientras que la donación de esperma no supone una amenaza a la presunción de paternidad. Esto explica en parte por qué la donación de esperma no produce una controversia legal o moral en los países europeos donde la donación de gametos está permitida, y, en cambio, la donación de óvulos no siempre se acepta.

Además de la relación entre técnicas de reproducción asistida y reglas de filiación, otro elemento importante a tener en cuenta es la evolución que las técnicas de reproducción asistida han tenido en nuestras sociedades, donde se ha generalizado y normalizado su uso.

Las técnicas de reproducción humana asistida gozan de una gran aceptación por parte de la opinión pública europea, a pesar de la oposición de la Iglesia Católica ${ }^{8}$ (aunque en el caso de la reproducción humana asistida no tiene una posición tan activa como en el caso del aborto), del Islam o del judaísmo (Casado, 1997).

La domesticación de las técnicas reproductivas ha contribuido a la aceptación de estas intervenciones médicas en Europa. Se entiende como domesticación el proceso por el que algo que previamente se consideraba como desconocido o limitado al conocimiento científico se convierte en común e incluso familiar (Lie, 2015). En el caso de las técnicas reproductivas esto ha ocurrido a través del uso de imágenes fuera del cuerpo de la mujer (ecografías y otras pruebas de imagen).

Esta generalización ha cambiado también la definición de infertilidad: antes se consideraba que una pareja que no podía concebir un hijo/a de manera natural tenía problemas de fertilidad. Ahora, una pareja no se considera que tenga problemas de fertilidad hasta que no han pasado por al menos tres intentos de fertilización in vitro. De esta manera incluso el lenguaje ha cambiado y ha evolucionado de técnicas «artificiales» a técnicas «reproductivas» (Lie, 2015). En España por ejemplo, las estadísticas muestran que en 2016, el 2,36\% de las mujeres adultas, y el 4,84\% de las mujeres entre 35 y 39 años, habían recibido algún tipo de tratamiento de fertilidad ${ }^{9}$.

\section{Algunos datos sobre la donación de óvulos en Europa que complican aún más el análisis}

Dada la diversidad legal entre los países europeos, es importante analizar cómo el Consejo de Europa ${ }^{10}$ aborda este tema. La jurisprudencia del Tribunal Europeo de Derechos Humanos (TEDH) ha establecido que los ciudadanos tienen derecho al acceso a las técnicas de reproducción humana asistida como parte de su derecho a la privacidad incluido en el artículo 8 de la Convención Europea de Derechos del Hombre (CEDH).

8 En 1987 la Sagrada Congregación para la Doctrina de la Fe emitió un documento conocido como Donum Vitae, que abordaba la moralidad de muchas de las nuevas técnicas de reproducción. El documento no rechaza el uso de la tecnología para hacer frente a problemas de fertilidad. Afirma que hay algunos métodos que son moralmente aceptables y otros no. Si una determinada intervención médica ayuda o asiste para que el matrimonio pueda reproducirse, se considera moralmente aceptable. Pero si la intervención consiste en reemplazar el acto matrimonial para poder engendrar vida, entonces dicha intervención es moralmente inadmisible.

9 Instituto Nacional de Estadística, 2017.

10 El Consejo de Europa es una organización supranacional, diferente a la Unión Europea. Su principal objetivo es defender la democracia, el Estado de Derecho y los derechos humanos. El principal instrumento normativo es la Convención Europea de Derechos Humanos, que se aplica e interpreta por el Tribunal Europeo de Derechos Humanos (TEDH). Para poder ser miembro de la Unión Europea, es imprescindible ser miembro del Consejo de Europa y haber ratificado la Convención Europea de Derechos Humanos. 
Sin embargo, este derecho no supone que los Estados miembros estén obligados a facilitar el acceso a las técnicas de reproducción humana asistida como una alternativa al derecho a la reproducción, especialmente si esto implica la utilización de gametos donados, que dependen de la solidaridad de otros ciudadanos.

El derecho a ser un progenitor genético se interpretó incluido en el artículo 8 de la CEDH en el caso Dickinson c. Reino Unido ${ }^{11}$. El TEDH más tarde estableció el respeto a las decisiones sobre ser o no padre en el caso Evans c. Reino Unido ${ }^{12}$. También ha incluido varias veces en este artículo el derecho a tener un hijo/a y a utilizar las técnicas reproductivas para conseguirlo, como fue en el caso S.H. and others c. Austria ${ }^{13}$. En la mayoría de sentencias relativas a las técnicas reproductivas, el TEDH ha considerado que era necesario respetar un margen de apreciación nacional como exigencia de una sociedad democrática. De esta manera está implícitamente favoreciendo el turismo reproductivo (Van Hoof y Pennings, 2012b; Farnós, 2016).

Por tanto, no existe un reconocimiento del derecho a la reproducción de aquellas parejas que necesitan gametos donados (Van Hoof y Pennings, 2012b). El Tribunal reconoce el derecho a la reproducción bajo el artículo 8 en algunos casos, pero ese derecho puede estar limitado por los derechos de los donantes, los derechos de los niños y otros valores sociales. Además, al carecer la Unión Europea de competencias sobre técnicas de reproducción humana asistida y adopción, la libertad de movimientos de personas, servicios, bienes y capital dentro del espacio común europeo facilita que nacionales de un Estado miembro viajen a otro para acceder a ciertas técnicas reproductivas que gozan de legislaciones más permisivas (por ejemplo permitiendo la donación de óvulos). Este es el llamado «turismo reproductivo» o «salud reproductiva transnacional».

Por ejemplo, España es uno de los Estados miembros con mayores tasas de actividad en reproducción humana asistida, con aproximadamente 55.000 ciclos de fertilización in vitro (FIV) al año, y 10.000 pacientes extranjeras ${ }^{14}$. Las clínicas de fertilidad españolas acaparan el 35-40 por ciento del turismo reproductivo de Europa, y la mayoría de los pacientes vienen de Italia, Francia y el Reino Unido (Fundación EOI, 2013). Cataluña es la comunidad autónoma de España con el mayor ratio de clínicas de fertilidad (mayoritariamente privadas) y de tratamientos de fertilidad. Casi la mitad de las mujeres que reciben óvulos donados en Cataluña viven en el extranjero ${ }^{15}$.

Asimismo, dado que solo unos pocos países europeos mantienen el anonimato en la donación de óvulos, la búsqueda de óvulos representa una parte importante de este turismo reproductivo. Algunas investigaciones han calculado que aproximadamente el 62 por ciento de los óvulos utilizados en reproducción humana asistida en Europa provienen de donantes españolas (Shenfield et al., 2010). En España se llevaron a cabo 12.632 ciclos utilizando óvulos donados, y 6.313 bebés nacieron vivos de óvulos donados en $2014^{16}$.

España se ha convertido en un destino turístico atractivo, particularmente la costa mediterránea con sus hoteles, aeropuertos, restaurantes y la posibilidad de comunicarse en ingles con el personal médico en las clínicas de fertilidad (Halmø, 2014).

\footnotetext{
Caso 44362/04, Sec. $4^{\text {a }}$ 18.4.2006, rev. Grand Chamber 4.12.2007

Caso 6339/05, Sec. $4^{\text {a }} 7.3 .2006$, conf. Grand Chamber 10.4.2007

Caso 57813/00, Sec. $1^{\text {a }} 1.4 .2010$, rev. 2010 Chamber 3.11.2011

Sociedad Española de Fertilidad, 2012

FIVCAT.NET Estadísticas sobre Reproducción Humana Asistida en Cataluña, 2013.

Informe estadístico sobre técnicas de reproducción asistida, 2014.
} 
También ha contribuido la existencia de una legislación más permisiva en materia de técnicas de reproducción asistida y de planificación familiar, la existencia de suficientes donantes como para evitar listas de espera y el carácter anónimo de la donación de gametos (Pennings, 2007).

Pero este turismo reproductivo provoca cierta polémica política y moral. Algunos autores como Pennings (2004) mantienen una posición tolerante y afirman que cuando la mayoría de la sociedad prohíbe ciertas técnicas de reproducción humana asistida, la minoría encuentra en el viajar a otros países para acceder a estas técnicas una forma de válvula de escape moral. Esta especie de objeción moral de conciencia permite a la sociedad vivir en paz. Este autor considera que incluso prohibir el turismo reproductivo representaría una violación de la agencia moral de los ciudadanos; por eso, más que el término peyorativo de «turismo reproductivo», prefiere utilizar «salud reproductiva transnacional» (Pennings, 2006).

La mayoría de los países se muestran bastante tolerantes con este turismo reproductivo que mantiene calmada a ciertas élites socio-económicas que, de otra forma, ejercerían una importante presión para cambiar la legislación. Excepcionalmente, algunos países han utilizado el principio de extraterritorialidad para criminalizar y perseguir a sus nacionales cuando acceden en terceros países a técnicas prohibidas en sus ordenamientos jurídicos ${ }^{17}$. La aplicación del principio de extraterritorialidad se justifica por el principio de nacionalidad, que permite a un Estado extender su jurisdicción a sus ciudadanos independientemente de dónde tuvo lugar el acto (Van Hoof y Pennings, 2012a; Cohen, 2014).

Otros autores tienen en cambio una visión negativa del turismo reproductivo (Farnós, 2016; Gupta, 2006), y consideran que aumenta el riesgo de discriminación por clase social, fomenta las situaciones de explotación y puede hacer disminuir la calidad de los tratamientos de fertilidad. Farnós (2016) considera el turismo reproductivo como un ejemplo de doble moral: lo que internamente está prohibido porque es moralmente controvertido, en cambio se tolera en el extranjero. Cree que esto contribuye a la comercialización de un sector que no puede dejarse al arbitrio del libre mercado y evita un debate público que resulta esencial en una sociedad democrática cuando se abordan cuestiones moral y éticamente controvertidas. Gupta (2006) también critica el turismo reproductivo porque considera que no está basado en la solidaridad mutual entre mujeres y que, en cambio, contribuye a su explotación en un contexto globalizado neoliberal.

A pesar de estas posiciones divididas, el turismo reproductivo sigue aumentando y generalizándose en el espacio común europeo, especialmente desde el caso Decker and Kohll 1998 en el Tribunal de Justicia Europeo ${ }^{18}$ que determinó que los servicios sanitarios eran una provisión de servicios susceptibles de intercambio dentro del espacio europeo (Pennings, 2007). La sentencia hizo florecer nuevos dilemas sobre la cobertura sanitaria pública como, por ejemplo, las técnicas de reproducción humana asistida.

La Directiva 2011/24/UE del Parlamento Europeo y del Consejo de 9 de marzo de 2011, relativa a la aplicación de los derechos de los pacientes en la asistencia sanitaria transfronteriza, supone un paso hacia la armonización de la diversidad legal sobre técnicas de reproducción humana asistida en Europa. Antes de esta Directiva,

\footnotetext{
17 Es el caso de Turquía sobre el uso de gametos donados, o los estados australianos de Nueva Gales del Sur o Queensland con sus ciudadanos cuando acceden a la gestación por sustitución comercial.

18 Kohll and Decker, 28 Abril 1998, casos C-120/95 y C-158/96
} 
preocupaba la posibilidad de que el sistema público de sanidad de un país tuviera que reembolsar los gastos de tratamientos de fertilidad acaecidos en otro Estado miembro, tratamientos que quizá ni siquiera eran legales en el primer país. Una enmienda de la Directiva que excluía algunos de los servicios sanitarios más controvertidos como la eutanasia, los test de ADN y ciertas técnicas reproductivas solucionó este problema (Van Hoof y Pennings, 2012b).

\section{Argumentos para legitimar la donación anónima de óvulos}

Uno de los principales argumentos a favor de la donación anónima de óvulos es la existencia de un instinto maternal que empuja a las mujeres a buscar óvulos donados o acudir a la adopción con tal de convertirse en madres. La creencia en un instinto maternal de carácter natural y biológicamente determinado está fuertemente presente en nuestra cultura. Tanto hombres como mujeres han sido socializados para creer en la existencia de un instinto maternal que explica los roles de género diferentes, y que justifican la asignación de la responsabilidad de cuidados a las mujeres en una sociedad organizada alrededor de la división sexual del trabajo (Igareda, 2012b). A pesar de las numerosas críticas de este determinismo biológico desde la antropología, la sociología y el feminismo (Beauvoir, 1949; Rich, 1976; Badinter, 1980), este instinto maternal está aún muy presente en nuestra sociedad. Muchas mujeres todavía otorgan gran importancia y significado a la experiencia maternal, tengan o no relación genética con el bebé.

Otro de los argumentos para defender la donación de óvulos es que la mayoría de las donantes vienen de países con una larga e importante trayectoria de donación altruista que incluye otras partes del cuerpo, como sangre u órganos. España es un país líder en donación de órganos ${ }^{19}$, de sangre y otros actos altruistas por parte de sus ciudadanos (Shenfield et al., 2010). A pesar de ello, algunos estudios sobre donación de óvulos en España (ver por ejemplo Orobitg, Bestard y Salazar, 2013) señalan diferentes motivaciones para la donación. Inicialmente la principal motivación es el altruismo, aunque a medida que avanza el proceso y aumentan los inconvenientes físicos y vitales la compensación económica gana importancia.

Ciertos discursos acerca de la donación de gametos en España ayudan a justificar este acto como una verdadera «donación»: el extendido estereotipo de que los donantes son jóvenes universitarios; la creencia de que la donación está motivada por un deseo de «donar vida»; o el hecho de enfatizar el carácter altruista utilizando el término «compensación» en vez de «pago» (Álvarez, 2008).

También se defiende la necesidad de que esta donación tenga carácter anónimo, y se justifica para evitar las posibles consecuencias negativas en las relaciones familiares si se descubre la forma de concepción del niño/a: se teme que se produzca una pérdida de confianza en el seno de la familia, que se generen sentimientos negativos por ser diferente o por no tener continuidad genética por parte de algunos otros miembros de la familia, y que se produzca frustración por no poder identificar al donante (Turney y Coyle, 2000). Igualmente se teme la posibilidad de producir

19 En 2016, se produjeron 2.018 donaciones de órganos, y se realizaron 4.818 trasplantes de órganos. España es el líder mundial en donación de órganos durante varios años consecutivos (Ministerio de Sanidad, Servicios Sociales e Igualdad). 
relaciones desiguales con los padres cuando uno de ellos tiene vínculo genético y el otro no (Landau, 1998).

La mayoría de las veces, los padres no revelan esta forma de concepción porque no lo consideran necesario. Consideran que es algo personal, íntimo y privado, y temen el rechazo por parte de otros miembros de la familia. A pesar de que la intención es garantizar el bienestar de los menores, al final el principal motivo es protegerse a sí mismos, ya que los problemas de fertilidad siguen acarreando cierto estigma social (Readings el al., 2011). Además, incluso en aquellos países donde el anonimato de la donación ha sido eliminado, no existe obligación legal de informar a los menores que han sido concebidos mediante gametos donados (Igareda, 2014).

Otro argumento para defender el anonimato de la donación de óvulos (y esperma) es que en los países donde la donación de gametos no es anónima, el perfil del donante cambia, son en mayor medida personas casadas que ya tienen hijos/as, lo que puede implicar mayores posibilidades de anomalías congénitas por la edad. Estos donantes son más proclives a buscar un eventual contacto y relación con el menor, lo que suscita una preocupación de que pueda interferir en la vida familiar de ese menor (Pennings, 1997).

El anonimato también beneficia a una creciente y productiva industria de la fertilidad, que mueve mucho dinero y prestigio (Igareda, 2014). El desarrollo de esta industria se presenta como una respuesta a una demanda creciente de las mujeres. Las críticas morales se dirigen normalmente a las mujeres y no al negocio de la reproducción: por ejemplo, el hecho de que las mujeres son capaces de enormes esfuerzos físicos y económicos para tener un hijo/a a cualquier precio, incluso en contra de los límites de la naturaleza (como es el caso de las mujeres postmenopáusicas ${ }^{20}$, las lesbianas o las médicamente infértiles) (Lema, 1999). Sin embargo, apenas se presta atención a los factores sociales, económicos y laborales que explican por qué las mujeres postergan su decisión de tener un hijo/a. Esta falta de cuestionamiento sobre los factores sociales que contribuyen a posponer la decisión de tener un hijo/a convierte así lo que inicialmente es una infertilidad social en una infertilidad biológica $\left(\right.$ Igareda, 2012b) ${ }^{21}$.

\section{Problemas y críticas a la donación de óvulos}

Algunas voces críticas con la donación de óvulos afirman que si se tratara de un acto realmente altruista no sería necesario proteger la identidad del donante. La reproducción asistida se entendería así como reproducción colaborativa y no como un negocio únicamente individual como se entiende actualmente (Puigpelat, 2012).

Las donantes de óvulos ocultan su donación debido a la falta de entendimiento social y familiar, ya que impera en la sociedad las ideas que asocian la genética con la relación de parentesco. Existe en este sentido una cierta contradicción entre la aceptación social de la donación de óvulos en abstracto, y el estigma que aparece frente a una donación concreta y de una conocida (Álvarez, 2008).

20 En España, el 67,72 por ciento de las mujeres que reciben óvulos donados tienen más de 40 años (Informe estadístico de técnicas de reproducción asistida, 2014).

21 La edad maternal avanzada es la principal razón para el diagnóstico genético pre-implantacional y representa el 40,2 por ciento de los casos en España (Informe Estadístico de Técnicas de Reproducción Asistida, 2014). 
Los cuestionamientos sobre su carácter altruista también se producen por la compensación económica que los donantes reciben. El perfil de los/as donantes sugiere que la compensación económica es un factor muy importante, cuando no la principal razón para someterse a unos procesos de donación gravosos, dolorosos y peligrosos que implican un control clínico, medicación diaria y cirugía bajo sedación para conseguir el resultado buscado (Spaar, 2007; Raposo, 2010).

En España por ejemplo, el perfil de las donantes de óvulos ha cambiado durante los años de la crisis económica. Aproximadamente el 60 por ciento de las donantes de óvulos eran mujeres extranjeras antes del 2011, y a partir de este momento el porcentaje de donantes universitarias comenzó a incrementarse considerablemente. También se produjo un cambio similar en el perfil de los donantes de semen (Álvarez, 2015). Las estadísticas catalanas muestran por ejemplo que aunque el 100 por cien de las donantes de óvulos afirman vivir en Cataluña, el 25 por ciento han nacido en el extranjero ${ }^{22}$.

A las receptoras de los óvulos donados les preocupa el origen de los óvulos con los que van a concebir a sus hijos/as. Normalmente aspiran a tener la mayor similitud fenotípica posible (la ley también refuerza este deseo ${ }^{23}$ ). Si las donantes son estudiantes universitarias españolas es más fácil encontrar esta similitud fenotípica, convencerse de que la motivación principal es el altruismo (no donan buscando dinero) e imaginar que genes más inteligentes serán heredados por sus hijos/as (Álvarez, 2008). Sin embargo la búsqueda por la similitud fenotípica no siempre es tan inocente y muchas veces esconde un cierto discurso racista. En España, las clínicas de fertilidad buscan donantes blancas que concuerden con la demanda proveniente del Norte de Europa. Las donantes de países de Europa del Este están muy buscadas (Halmø, 2014), y en cambio a veces las potenciales donantes de Latinoamérica son rechazadas por el color de su piel (Álvarez, 2008).

Además el carácter altruista termina con la donación. Las clínicas cobran unos honorarios muy altos a las mujeres que buscan óvulos donados para la reproducción asistida. Las clínicas se benefician por tanto de este acto altruista de las donantes y de la llamada solidaridad entre mujeres (Gupta, 2006).

Otro argumento en contra de la donación de óvulos son los riesgos inherentes en el proceso. Todavía no existen suficientes investigaciones exhaustivas sobre los posibles efectos secundarios de la donación de óvulos (Romeo Casabona, Paslack y Simon, 2013). Algunos estudios científicos han demostrado que pueden aparecer importantes efectos secundarios de la estimulación ovárica, además de los riesgos normales asociados a la intervención quirúrgica para obtener óvulos (Galpern, 2006). Se pone en duda también si a las potenciales donantes de óvulos se les facilita información adecuada sobre los posibles efectos secundarios y consecuencias para la salud de la donación (Álvarez, 2015).

Un problema añadido en España, uno de los pocos países europeos que permite la donación anónima de gametos, es que el Registro Nacional de Donantes previsto en la primera ley de técnicas de reproducción humana asistida de 1988 aún no se ha creado $^{24}$. Este incumplimiento legal provoca que la responsabilidad de cumplir con

22 FIVCAT.NET Estadísticas sobre Reproducción Asistida en Cataluña, 2013.

23 El artículo 5.5. de la Ley española 14/2006, de 26 de mayo, sobre técnicas de reproducción humana asistida señala que el personal médico debe buscar la mayor similitud fenotípica e inmunológica posible entre los donantes y las beneficiarias.

24 La primera ley 35/1988, de 22 de diciembre, sobre técnicas de reproducción asistida. 
el máximo legal de seis bebés nacidos vivos de cada donante se deje en manos de cada donante, teniendo que confiar en la honestidad y la información que proporciona a la clínica de fertilidad cuando dona sus gametos (Romeo Casabona, Paslac y Simon, 2013; Alvarez, 2015).

El anonimato constituye otra fuente de controversia, especialmente desde que España es uno de los pocos países que permite la donación de gametos anónima. El derecho a conocer los orígenes se ha considerado un derecho fundamental y esencial para la formación de la identidad personal y el disfrute de un bienestar emocional (Besson, 2007). De hecho, el término «desconcierto genealógico» (genealogical bewilderment) se utiliza para referirse a los menores que desconocen quiénes son sus verdaderos padres, reconociendo así que esto puede causarles cierto daño psicológico (Sants, 1964).

La Convención de los Derechos del $\mathrm{Niño}^{25}$ de las Naciones Unidas reconoce en su artículo 7 el derecho a conocer a sus padres y a ser cuidado por ellos en la medida de lo posible, lo que se ha interpretado de manera amplia como los padres biológicos y los sociales (Besson, 2007; Freeman, 1996). Sin embargo, este artículo sufre diferentes interpretaciones cuando es traducido a cada país: algunos países no admiten el anonimato en la donación de gametos y otros sí (Igareda, 2014). Muchos países europeos precisamente han modificado su legislación sobre donación anónima de gametos precisamente para garantizar este derecho de los menores (Alkorta y Farnós, 2017). Hasta la década de los 80 , a los padres se les recomendaba no desvelar cuáles eran los orígenes genéticos de los niños/as, pero posteriormente, los expertos empezaron a recomendar lo contrario, basándose en los resultados de investigaciones sobre adopción (Readings et al., 2011; Palacios y Brodzinsky, 2010). La generalización de las técnicas de reproducción humana asistida también ha contribuido a este cambio de estrategia.

El secreto alrededor de las circunstancias del nacimiento del menor va en contra de las relaciones familiares, ya que daña los lazos de confianza inherentes en la estructura familiar e interfiere con la seguridad del vínculo que todo menor necesita. El secreto es contrario a los intereses de los menores, y también es difícil de mantener debido a los parecidos físicos y a los registros médicos. El porcentaje de padres que expresan su intención de desvelar el uso de gametos donados a sus hijos/as es superior al de los padres que manifiestan su intención de no hacerlo. El porcentaje es además superior en el caso de donantes de óvulos que en el de esperma, seguramente influidos por el mayor estigma que los hombres asocian a la infertilidad.

La donación anónima de óvulos contradice la regulación de la adopción y el derecho del menor a conocer sus orígenes (Quesada, 2006; Alkorta y Farnós, 2017). El progresivo reconocimiento de este derecho no ha provocado grandes controversias éticas ni ha impedido un reconocimiento de la maternidad y paternidad social por encima de los vínculos genéticos y biológicos (Velázquez, 2010; Garrina, 2010).

A pesar de ello, la mayoría de la literatura sobre las consecuencias negativas de no conocer los orígenes biológicos ha sido elaborada en el campo de la adopción. Por tanto, algunos autores dudan de que pueda ser extrapolada al mundo de las técnicas de reproducción asistida: los menores concebidos mediante gametos anónimos donados no han sido abandonados por sus familias de origen y tienen vínculos genéticos con al menos uno de sus progenitores (Shenfield, 1994; Shenfield y Steele, 1997).

25 Adoptada en 1989, y entró en vigor en 1990. 
Algunos autores/as defienden que permitir acceder a la identidad del donante garantiza por un lado el derecho a conocer los orígenes y, por otro lado, se reconoce la relación colaborativa que hay detrás de las técnicas reproductivas (la llamada solidaridad entre mujeres), lo que a su vez minimizaría los posibles abusos de la industria de la fertilidad (Puigpelat, 2012).

La supresión del anonimato facilitaría la donación por parte de personas más altruistas, a la vez que desanimaría a aquellas únicamente motivadas por el dinero. Igualmente funcionaría como una forma de prevención frente a las personas en una situación de mayor desventaja económica, que pueden ser más vulnerables a la explotación económica (Puigpelat, 2012; Igareda, 2014).

\section{El ambiguo discurso sobre donar vida}

A pesar de las dudas sobre el carácter verdaderamente altruista de la donación de gametos, la publicidad utilizada por las clínicas públicas y privadas para atraer potenciales donantes hace hincapié en la naturaleza altruista de la donación, e invita a potenciales donantes a «donar vida» ${ }^{26}$. No obstante, la forma más frecuente de atraer donantes de gametos es el boca-oreja, cuando una persona que ya ha sido donante informa a un amigo/a para que acuda a la misma clínica. La segunda forma más frecuente es cuando un potencial donante es consciente del problema a través de un familiar o amigo/a con problemas de fertilidad y decide convertirse en donante para ayudar a otros/as en la misma situación. Y en tercer lugar, en los centros públicos españoles, la pareja debe proporcionar la donante de óvulos ella misma. Para poder cumplir con el mandato legal de anonimato, posteriormente, la clínica crea sistemas de intercambio de óvulos entre las diferentes parejas que acuden. En estos casos, las parejas normalmente consiguen las donantes de óvulos a través de familiares o internet (Álvarez, 2015).

Sin embargo en la publicidad de las clínicas y en la charlas sobre donación, los óvulos se describen como células sobrantes que pueden darse a otra mujer, y que si no, se perderían. En este proceso los óvulos se transforman en un símbolo de solidaridad entre mujeres (Orobitg, Bestard y Salazar, 2013).

Los óvulos humanos pasan de tener poco valor (vistos de manera metafórica como material «sobrante» o «desperdiciado») para convertirse cuando se unen a otros cuerpos en materiales de inmenso o potencial valor (óvulos «inteligentes»o mi futuro bebé) (Halmø, 2014:60) ${ }^{27}$.

El altruismo también se cuestiona cuando solo mujeres de una posición económica y social más desfavorecida son quienes se convierten en donantes. Mientras tanto, y dados los altos costes económicos de los tratamientos de fertilidad del sector privado,

26 En algunos países como en España, la legislación sobre técnicas reproductivas solo permite publicidad en la medida en que aluda al carácter altruista de la donación. Ver el artículo 5.3 de la Ley 14/2006, de 26 de mayo, sobre técnicas de reproducción humana asistida.

27 Traducción de la autora de: «Human oöcytes move from having little value (rhetorically framed as 'excess' or 'waste'? material) to, in their encounter with other bodies, producing effects of immense value ('intelligent' eggs) or potential (my future baby)». 
solo las mujeres de clase social alta o con elevados ingresos económicos pueden costearse estos tratamientos y los ciclos de donación. En ocasiones, las donantes de óvulos son conscientes de las desigualdades de clase social entre ellas y las receptoras de sus óvulos donados; sin embargo, cuando su discurso se analiza en investigaciones sociológicas y antropológicas, el argumento de la solidaridad parece compensar cualquier posible crítica de injusticia social (Orobitg, Bestard y Salazar, 2013).

En conclusión, el discurso de «dar y recibir vida» coloca la donación de óvulos, de órganos y de sangre en la misma categoría. Este hecho se intensifica en España, que se ha convertido en el país líder de actos altruistas como la donación y el trasplante de órganos, la donación de sangre y de óvulos. Sin embargo, el tratamiento legal de estas formas de donación es muy diferente: a diferencia de los órganos ${ }^{28}$ y de la sangre, la donación de óvulos no está gestionada de manera exclusiva por entidades públicas. Y solo en el caso de la donación de óvulos y esperma existe algún tipo de compensación económica y entidades privadas (clínicas de fertilidad, personal médico y bancos de gametos) se benefician económicamente de estas donaciones.

\section{Bibliografía}

Ahumada, Marcela A. (2008). «La clonación humana y el resguardo de los intereses de las mujeres». Revista de Derecho y Genoma Humano, 28: 33-57.

Alkorta, Itziar (2006). «Women's Rights in European Fertility Medicine Regulation», en S. Widdows, S., Alkorta, I., Emaldi, A. Women's reproductive rights. London: Palgram Macmillan.

Alkorta, Itziar; Farnós, Esther (2017): «Anonimato del Donante y Derecho a Conocer: un Difícil Equilibrio», Oñati socio-legal series, 7 (1): 2148-178.

Álvarez, Consuelo (2008). «La materia humana en un alambique: nuevos modos de engendrar y la asimetría de la donación de semen y óvulos», en A. Piella, L. Sanjuán, H. Valenzuela (coords.). Construyendo intersecciones: aproximaciones teóricas y aplicadas en las relaciones entre los ámbitos del parentesco y la atención a la salud en contexto intercultural. San Sebastián: Congreso de Antropología (11. 2008. San Sebastián), 65-81.

Álvarez, Consuelo (2015). «Sexo sin reproducción y reproducción sin sexo. Sexualidad y salud reproductiva de los donantes de semen y óvulos». Revista de Dialectología y Tradiciones Populares, vol. LXX: 469-484.

Badinter, Elisabeth (1980). L'amour en plus. Histoire de l'amour maternel (XVIIe - XXe siècle). Paris: Flammarion.

Beauvoir, Simone (Ed.) (1949, 2001a vol. I, 2001b vol. II). El segundo sexo. Madrid: Cátedra.

Besson, Samantha (2007). «Enforcing the child's right to know her origins: contrasting approaches under the Convention on the Rights of the Child and the European Convention on Human Rights». International Journal of Law, Policy and the Family, 21 (2): 137-159.

Casado, María (1997). «Reproducción humana asistida: los problemas que suscita la bioética y el derecho». Papers: revista de sociología, 53: 37-44.

Cohen, Glenn (2014). «Las fronteras del derecho sanitario: globalización y turismo médico». Anuario de la Facultad de Derecho de la Universidad Autónoma de Madrid, 18: 21-44.

28 Este es el caso de la Organización Nacional de Trasplantes, un organismo público del Ministerio de Sanidad, Servicios Sociales e Igualdad. 
Farnós, Esther (2016). «La reproducción asistida ante el Tribunal Europeo de Derechos Humanos: De Evans c. Reino Unido a Parrillo c. Italia». Revista de Bioética y Derecho, 36: 93-111.

Fundación EOI (2013). Turismo de salud en España. Madrid: Ministerio de Industria, Energía y Turismo, Secretaría de Estado de Turismo.

Galpern, Emily (2006). «Beyond Embrio Politics: Women's Health and Dignity in Stem Cell Research». National Women's Health Network, May/June 2006: 1-4.

Garrina, Margarita (2010). La adopción y el derecho a conocer la filiación de origen: un estudio legislativo y jurisprudencial. Madrid: Aranzadi.

Golombok, Ssusan (2012). «Nuevas formas familiares» en Esteinou, R. (Coord.). La nueva generación social de familias. Tecnologías de reproducción asistida y temas contemporáneos. México: Centro de Investigaciones y Estudios Superiores en Antropología Social, 43-74.

Generalitat de Catalunya (2016). FIVCAT.NET Statistics on Human Assisted Reproduction in Catalonia, 2013. Barcelona: Department of Health, Government of Catalonia.

Gupta, Jyostna A. (2006). «Towards Transnational Feminism». European Journal of Women's Studies, 13 (1): 23-38.

Halmø, Charlotte (2014). «West is best: Affective assemblages and Spanish oöcytes». European Journal of Women's Studies, 21(1): 57-71.

Igareda, Noelia (2012a). «Las mujeres como objeto y no como sujeto de las técnicas de reproducción humana asistida», en M. Boladeras (ed.). Bioética, género y diversidad cultural. Barcelona: Cánoves i Samoles, Proteus, 447-490.

- (2012b). De la protección de la maternidad a una legislación sobre el cuidado. Saarbrücken: Editorial Académica Española.

- (2014). «El derecho a conocer los orígenes biológicos versus el anonimato en la donación de gametos». Derechos y Libertades, 31: 227-249.

Landau, Ruth (1998). «The management of genetic origins: secrecy and openness in donor assisted conception in Israel and elsewhere». Human Reproduction, 13: 3268-3273.

Lema, Carlos (1999) Reproducción, poder y derecho. Madrid: Trotta.

Lie, Merete (2015). «Reproduction inside/outside: medical imaging and the domestication of assisted reproductive technologies». European Journal of Women's Studies, 22 (1): 53-69.

Ministry of Health, Social Affairs and Equality (2014). Statistical report of Assisted Reproductive Techniques. Madrid: Ministry of Health, Social Affairs and Equality.

Orobitg, Gemma; Bestard, Joan; Salazar, Carles (2013). «El cuerpo (re) productivo. Interés económico y altruismo social en las experiencias de un grupo de mujeres donantes de óvulos». Revista andaluza de Antropología, 5: 91-104.

Pennings, Guido (1997). «The «double track» policy for donor anonymity». Human Reproduction, 12 (12): 2839-2844.

- (2004). «Legal harmonization and reproductive tourism in Europe», Human Reproduction, 19 (12): 2689-2694.

- (2006). «International parenthood via procreative tourism», en F. Shenfield, Cl. Sureau (eds.). Contemporary ethical dilemmas in assisted reproduction, Abingdon. Oxon: Informa Health Care, 43-56.

- (2007). «Ethics without boundaries: medical tourism», en R. Ashcroft, A. Dawson, H. Draper et al. (eds.). Principles of health care ethics. London: John Wiley \& Sons, 505-510.

Quesada, Maria Corona (2006). «La Convención ante los procesos de adopción», en C. Villagrasa, I. Ravetllat (coords). El desarrollo de la Convención sobre los Derechos del Niño en España. Barcelona: Bosch, 141-142. 
Palacios, Jesus; Brodzinsky, David (2010). «Adoption research: trends, topics, outcomes». International Journal Bhaviour Deviance, 34: 270-284.

Raposo, Vera Lucía (2012). «Contratos de donación de gametos: ¿regalo de vida o venta de material genético?». Revista de Derecho y Genoma Humano, 37: 93-122.

Puigpelat, Francesca (2012). «El anonimato de las donaciones en las técnicas de reproducción asistida: una solución insatisfactoria desde una perspectiva feminista», en M. Casado, A. Royes (coords.). Sobre Bioética y Género, Barcelona: Aranzadi.

Readings, Jennifer; Blake, Lucy; Casey, Polly; et al. (2011). «Secrecy, disclosure and everything in-between: decisions of parents of children conceived by donor insemination, egg donation and surrogacy». Reproductive BioMedicine Online, 22 (6): 653-654.

Rich, Adrianne (1976). Of woman born. London: Virago.

Romeo Casabona, Carlos M.; Paslack, R.; Simon, Jurgen W. (2013). «Reproductive Medicine and the Law: Egg Donation in Germany, Spain and other European Countries». Revista de Derecho y Genoma Humano, 38: 15-42.

Sants, H. (1964). «Genealogical bewilderment in children with substitute parents». British Journal Medical Psychology, 37: 133-141.

Shenfield, Francoise (1994). «Filiation in assisted reproduction: potential conflicts and legal implications». Human Reproduction, 9: 1348-1354.

Shenfield, Francoise; Steele, Stuart J. (1997). «What are the effects of anonymity and secrecy on the welfare of the child in gamete donation?». Human Reproduction, 12 (2): 392-395.

Shenfield, Francoise; De Mouzon, Jacques; Pennings, Guido; et al. (2010). «Cross border reproductive care in six European countries». Human Reproduction, 25 (6): 1361-1368.

Spaar, Debora (2007). «The egg trade - making sense of the market for human oocytes». New England Journal of Medicine, 13:1289-1291.

Turner, A.; Coyle, A. (2000). «What does it mean to be a donor offspring' The identity experiences of adults conceived by donor insemination and the implications for counselling and therapy». Human Reproduction, 15: 2041-2051.

Van Hoof, Wannes; Pennings, Guido (2012a). «Extraterritorial Laws for Cross-Border Reproductive Care: The Issue of Legal Diversity». European Journal of Health Law, 19: 187-200.

Van Hoof, Wannes; Pennings, Guido (2012b). «The consequences of S.H. and Others v. Austria for legislation on gamete donation in Europe: an ethical analysis of the European Court of Human Rights judgments». Reproductive Biomedicine Online, 25: 665-669.

Velázquez, Antonio J. (2010). «El derecho del adoptado a conocer sus orígenes biológicos». Diario La Ley, 7526.

Vidal, Jaime (2011). «Acerca de la sentencia del Tribunal Europeo de Derechos Humanos. Caso S.H. y Otros contra Austria. TEDH 2010/56 de 1 de abril, en materia de reproducción humana asistida y su incidencia en el panorama legislativo europeo». Revista Derecho Genoma Humano, 34: 155-201. 